\title{
Voluntary Commitments (VCs) under the UN Oceans Conference- Are VCs Advancing the Implementation of SDG 14?
}

\author{
Carolina Romero* \\ World Maritime University, Sweden
}

Submission: December 12, 2017; Published: February 16, 2018

*Corresponding author: Carolina Romero, Associate Professor, World Maritime University, Fishkehamnsgatan 1, 21118 Malmö, Sweden, Tel: 46-40-356359; Fax: 46-40-356310; Email: mcr@wmu.se

Abbreviations: SDG: Sustainable Development Goal 14; VCs: Voluntary Commitments

\section{Introduction}

The high-level United Nations Conference to Support the Implementation of Sustainable Development Goal 14: Conserve and sustainable use the oceans, seas and marine resources for sustainable development took place in New York in June 2017. While promising to be solutions-focused with engagement from all, it aimed at slowing down the decline in the health of the oceans, for the people, the planet and prosperity; and its outcome document "Our Ocean, Our Future: Call for Action" and the approximate 1,400 registered voluntary commitments (VCs) have been praised by the UN as a "global breakthrough on the path for the health of our oceans and seas".

While SDG 14 focuses on actions where there seems to be a lack of willingness, capability and cooperation from governments to reach agreements [1], VCs are a tool often used alongside official agreements and declarations in sustainable development efforts since the 2002 World Summit on Sustainable Development [2]. However, their effectiveness seems debatable as they also represent a scheme for avoiding obligations, they fail to engage all, and seldom deliver what was promised; moreover, their use in multiple forums distracts efforts towards taking decisive actions to ensure the sustainable conservation of the oceans. Consequently, the question of whether or not VCs constitute a solutions-focused approach is raised, together with the need to examine the Conference's achievement in connection with an engagement for all and lastly, their contribution towards the implementation of SDG 14.

\section{Are VCs A Proper Solution-Focused Mechanism?}

The rationale behind VCs lies in the insufficiency or incapacity of Member States to take "mandatory" or "required" decisions in sustainable development or climate forums, hence the need for new forms of non-legally binding instruments to ensure actions are taken within a given time frame, which in turn allows countries to agree on a course of action and engage wider audiences beyond their national governments. The element of flexibility in such non-negotiated, collaborative projects and partnerships often backfires as the lack of rigid constraints leaves actors free to choose the areas on which they are interested in committing. As an example, the fewest VCs are found in one of the most critical targets of SDG 14, overfishing and illegal, unreported and unregulated fishing. Due to their voluntary and complementary character, it is difficult to state that VCs are proper solution-focused mechanisms. I think they are complementary tools to enhance sustainable development efforts instead.

Have VCs Been Able to Engage us All After the Conference? Are there Gaps in Participation?

The idea behind VCs is to encourage stakeholder's engagement by ensuring the community participates in sustainable development programs. VCs have the capability to involve multiple stakeholders, intergovernmental and non-governmental organizations, multinational and national corporations, and innumerable networks, many of whom may make use of new technologies to support their causes [3]. As a result, VCs are also capable of leading initiatives where a commitment beyond compliance could be within reach, with the added benefit of potentially mobilizing or accessing additional founding.

The main contributors of VCs globally are governmental entities, with significant differences across all geographic 
regions. An analysis made at the VCs of the Oceans Conference showed that Eastern Europe's actions are led exclusively by governmental entities, while North America's main contributors are NGOs. The private sector is absent in VCs in the African Continent, the Middle East, Eastern Europe and Central America. In addition, it is important to point out that the sectors making the fewest contributions are academia (3\%), the scientific community (2\%) and philanthropic organizations (1\%) [4]. As we can see, the presence of gaps in global participation opens spaces for questioning the engagement of all.

\section{Do VCs Really Represent Advantages?}

It can be said that VCs embody a «nothing-to-lose» approach. Even when failing, there is always a net gain, because nothing would have happened if there had not been a VC in the first place. A successful example is the Partnership for Clean Fuels and Vehicles that helped national ministries, agencies, groups from civil societies and UN agencies to work together in helping developing countries reduce air pollution by adopting clean fuels in vehicles [4]. In spite of their potential for achieving solutions to global problems, VCs also allow governments to circumvent their responsibilities and unfortunately are used by companies to enhance their reputation and for avoiding stricter regulations. If we look at "green washing" and "blue washing» practices by companies around UN Global Compact, there is a controversy regarding their social corporate responsibilities being undermined by their own VCs.

\section{How Many VCs Aimed at Achieving the Sustainable Use of the Oceans are Registered?}

Currently a growing number of UN and government-related initiatives have requested and published VCs. In addition to the 1406 VCs made at the Oceans Conference, other ocean forums have registered their own VCs as well, for example the Our Ocean Conference hosted by the European Union with its 437 generated commitments, and those from Our Oceans Conferences in 2016, 2015 and 2014. Similarly, commitments related to the oceans have been registered in Conferences on climate change or biodiversity, such as the Aichi Biodiversity targets in 2010. At the moment, the degree of overlap of these commitments is unknown; it is also difficult to determine whether VCs have been registered in more than one forum. Besides helping quantify current VCs, experience sharing should also be an important aim of the registry, which could help transfer knowledge among participants to help towards engaging all.

\section{Conclusion}

As shown above, VCs need to be looked upon more closely, considering that they seem to accomplish less than they set out to do as proper solution-focused mechanisms. Their flexibility is not necessarily a synonym of success; and advantages and disadvantages from previous experiences need to be kept in mind in order to be able to profit from these initiatives, which are also distorted by organizations wanting to evade their obligations.

The practice of registering VCs in different oceans forums will make it difficult to come to real figures for an overall assessment of the efficiency of the mechanism, which also raises issues of accountability. This new parallel system that was put in place somehow replicates the problems of oceans governance, but in a smaller scale, with duplication of VCs (mandates) in different forums, without a global registry and lacking an authority to monitor or manage all of them. An assessment of what VCs have achieved is critical also in order to assess their efficiency in the implementation of SDG 14. For all these reasons, there are doubts in relation to the contribution of VCs towards a real advancement in the implementation of SDG 14.

\section{References}

1. Romero Lares MC (2018) Algunas consideraciones en torno a las deficiencias de la Convención de las Naciones Unidas sobre el Derecho del Mar para contribuir a la gobernanza sostenible de los océanos. ACDI - Anuario Colombiano de Derecho Internacional, Sweden, p. 11. with Anuario Colombiano de Derecho Internacional (ACDI) (11): 135162.

2. Ramstein (2012) Rio+20 Voluntary Commitments: delivering promises on sustainable development. IDDRI Working Paper (23): 1-28.

3. Brown E (2014) Voluntary Commitments as Emerging Instruments in International Environmental Law. Environmental Policy and Law (44): 83-95.

4. UN DESA (2017) In depth analysis of Ocean Conference Voluntary Commitments to support and monitor their implementation, United Nations.
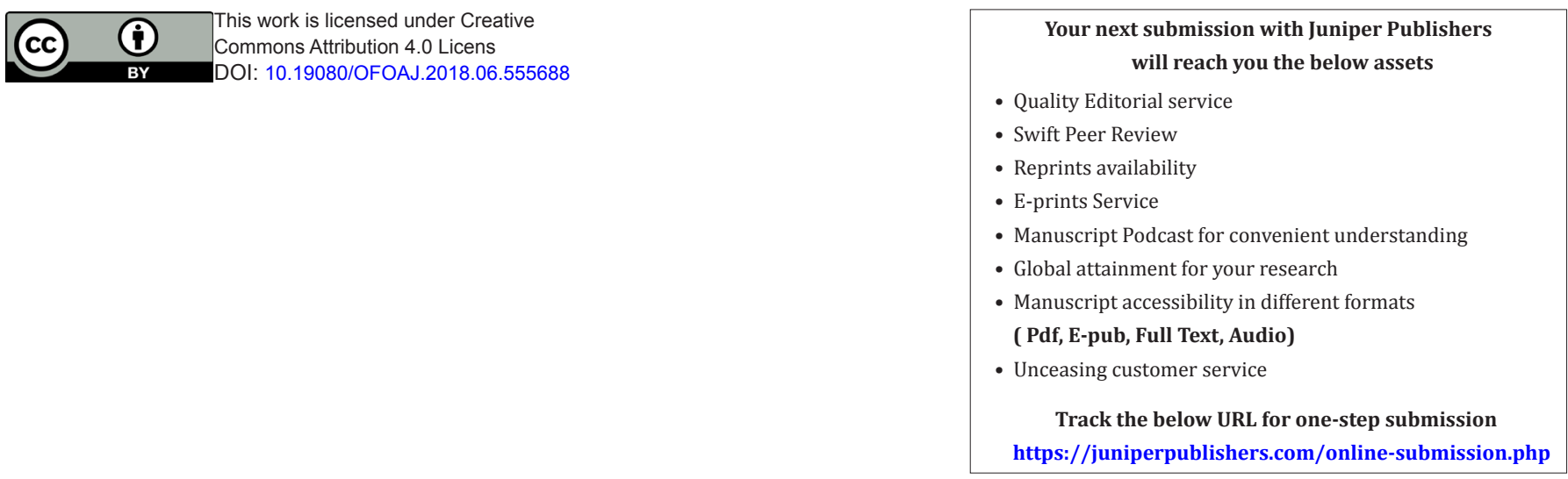